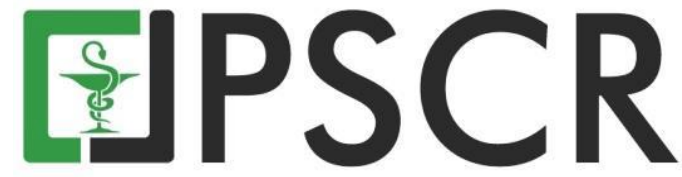

\title{
Analisis Persepsi Masyarakat Terhadap Peran Apoteker Pada Layanan Kefarmasian Di Apotek Kecamatan Sokaraja, Baturraden, Sumbang, Dan Kedungbanteng
}

\author{
Hening Pratiwi $^{1 *}$, Ika Mustikaningtias ${ }^{1}$, Fajri R. Widyartika ${ }^{1}$, Didik Setiawan ${ }^{2}$, Khafidz \\ Nasrudin $^{3}$ dan Leony Julietta ${ }^{3}$ \\ ${ }^{1}$ Jurusan Farmasi, Fakultas Ilmu-Ilmu Kesehatan, Universitas Jenderal Soedirman, Jl. dr. Soeparno Kampus \\ Karangwangkal Purwokerto, 53122 \\ ${ }^{2}$ Fakultas Farmasi Universitas Muhammadiyah Purwokerto, Jl. Raya Dukuhwaluh, Kabupaten Banyumas, 53182 \\ ${ }^{3}$ Pengurus Cabang Ikatan Apoteker Indonesia (PC IAI) Banyumas, Jl. Gerilya Barat No.286, Tanjung, \\ Kabupaten Banyumas, 53144 \\ *email korespondensi: hening.pratiwi@unsoed.ac.id
}

\begin{abstract}
Abstrak: Semakin tingginya tuntutan masyarakat dan semakin berkembangnya pelayanan yang diberikan menuntut apoteker harus mampu memenuhi keinginan dan tuntutan masyarakat yang beragam. Penilaian kualitas layanan kefarmasian dapat dilakukan dengan cara mengetahui persepsi masyarakat terhadap pelayanan yang sudah diterima dalam pemenuhan harapan masyarakat. Penelitian ini bertujuan untuk mengetahui kesadaran (general awareness), persepsi, harapan, dan pengalaman masyarakat terhadap peran apoteker dalam memberikan layanan kefarmasian di Apotek Kecamatan Sokaraja, Baturraden, Sumbang, dan Kedungbanteng. Penelitian ini merupakan penelitian non-eksperimental dengan metode observasional. Penentuan apotek sebagai lokasi penelitian dilakukan stratified random sampling pada 23 apotek dan pengambilan sampel responden dengan accidental sampling kepada 110 responden. Instrumen penelitian ini berupa kuesioner yang selanjutnya dilakukan skoring dan analisis univariat secara deskriptif. Kemudian dilakukan kategorisasi dengan berdasarkan nilai median. Analisis persepsi masyarakat terhadap peran apoteker di Apotek Kecamatan Sokaraja, Baturraden, Sumbang, dan Kedungbanteng memperoleh hasil diantaranya adalah sebanyak 65,45\% masyarakat memiliki kesadaran (general awareness) yang baik, 63,64\% memiliki persepsi baik, 59,09\% memiliki harapan yang baik, dan 50\% memiliki pengalaman yang baik terhadap peran apoteker pada layanan kefarmasian di apotek. Dapat disimpulkan bahwa kesadaran (general awareness), persepsi, harapan, dan pengalaman masyarakat terhadap peran apoteker di Apotek Kecamatan Sokaraja, Baturraden, Sumbang, dan Kedungbanteng cukup baik. Apoteker perlu menggunakan atribut praktik apoteker (jas atau name tag) di apotek untuk memudahkan masyarakat mengenali apoteker.
\end{abstract}

Kata kunci: Persepsi; Apoteker; Apotek; Layanan kefarmasian

Abstract. The increasing demands of the community and the growing development of services provides required pharmacists to be able to meet the desires and demands of a diverse community. Evaluation of the quality of pharmaceutical services can be done by knowing the public perceptions of services that have been received in fulfilling community expectations. This study aimed to determine general awareness, perceptions, hopes, and community experiences of the role of pharmacists in providing pharmaceutical services in Pharmacy Districts of Sokaraja, Baturraden, Sumbang, and Kedungbanteng. This research was a nonexperimental research with observational method. Determination of the pharmacy as a 
research location carried out stratified random sampling at 23 pharmacies and sampling respondents by accidental sampling to 110 respondents. The instrument of this study was in the form of a questionnaire which was subsequently performed scoring and univariate analysis descriptively. Then conducted the categorization based on the median value. Analysis of public perception of the role of pharmacists in the Pharmacy Districts of Sokaraja, Baturraden, Sumbang, and Kedungbanteng showed $65.45 \%$ of the public having good general awareness, $63.64 \%$ having good perception, $59.09 \%$ having hopes is good, and $50 \%$ have good experience of the role of pharmacists in pharmacy services at pharmacies. As conclusion that general awareness, perceptions, hopes and experiences of the community towards the role of pharmacists in the Pharmacy Districts of Sokaraja, Baturraden, Sumbang, and Kedungbanteng were quite good. Pharmacists need to use pharmacist practice attributes (suits or name tags) in pharmacies to make it easier for people to recognize pharmacists..

Keywords: Family planning; Interprofessional education; Knowledge; Perception

\section{Pendahuluan}

Pelayanan kesehatan memiliki peran penting dalam meningkatkan derajat kesehatan masyarakat, salah satunya dengan pelayanan kefarmasian yang dilakukan oleh apoteker di apotek (Wathoni dan Rahayu, 2014). Dalam rangka penjaminan mutu pelayanan kefarmasian, Indonesia telah memberlakukan standar pelayanan kefarmasian di apotek (Handayani et al., 2009). Pharmaceutical care merupakan pelayanan kefarmasian yang dilakukan oleh apoteker, bertanggung jawab kepada pasien, dan telah diatur dalam standar pelayanan kefarmasian di apotek (Kemenkes RI, 2016). Orientasi pelayanan kefarmasian saat ini telah bergeser dari drug oriented menjadi patient oriented. Pelayanan yang semula hanya berfokus pada pengelolaan obat harus bergeser menjadi pelayanan yang menyeluruh, baik pengelolaan obat maupun pelayanan kepada masyarakat. Hal tersebut bertujuan untuk meningkatkan kualitas hidup masyarakat (Handayani et al., 2009).

Semakin tingginya tuntutan masyarakat dan semakin berkembangnya pelayanan yang diberikan menuntut apoteker harus mampu memenuhi keinginan dan tuntutan masyarakat yang berubah-ubah dan beragam (Mulyani et al., 2013). Akibatnya, dibutuhkan eksistensi apoteker sebagai sumber daya manusia dalam hal peningkatan pengetahuan, keterampilan serta mampu berinteraksi dengan masyarakat. Dengan adanya interaksi, masyarakat dapat mengetahui kualitas pelayanan kefarmasian yang diberikan oleh apoteker serta mendapatkan manfaatnya (Fajarini, 2018). Penilaian kualitas pelayanan kefarmasian dapat dilakukan dengan cara mengetahui persepsi masyarakat terhadap layanan yang sudah diterima dalam pemenuhan harapan masyarakat. Ketika masyarakat belum mengetahui peran apoteker maka tujuan pemberian informasi obat kemungkinan kurang lengkap dan jelas sehingga dapat meningkatkan risiko terjadinya medication error dan dapat menurunkan tercapainya tujuan terapi (Hutami dan Rokhman, 2013; Winanto, 2013). 
Kabupaten Banyumas memiliki 195 apotek yang tersebar dalam 27 Kecamatan. Tingkat kehadiran apoteker yang ada di apotek - apotek Kabupaten Banyumas cukup tinggi yaitu 73\%, namun penerapan pelayanan kefarmasian sesuai dengan standar pelayanan kefarmasian masih termasuk kedalam kategori kurang yaitu 60,04\% (Aryunadi, 2014). Menurut Jin et al. (2014) 80,1\% masyarakat di Pakistan telah mengetahui apoteker dan menganggap apoteker sebagai sumber informasi obat serta meyakini apoteker sebagai anggota penting dalam tim pelayanan kesehatan. Analisis mengenai kesadaran (general awareness), persepsi, harapan serta pengalaman masyarakat terhadap peran apoteker dalam memberikan pelayanan kefarmasian perlu dilakukan di negara berkembang agar dapat dilakukan evaluasi untuk meningkatkan kualitas layanan (Jin et al., 2014).

Berdasarkan hal tersebut serta terkait dengan pentingnya eksistensi apoteker dalam lingkungan masyarakat perlu dilakukan penelitian analisis persepsi masyakarat terhadap peran apoteker dalam memberikan pelayanan kefarmasian di Apotek Kecamatan Sokaraja, Baturraden, Sumbang, dan Kedungbanteng untuk mengetahui seberapa besar masyarakat Banyumas mengenal profesi apoteker yang sesungguhnya dan berkaitan dengan upaya pengembangan dan peningkatan kualitas apoteker di Kabupaten Banyumas. Ada beberapa penelitian mengenai persepsi terhadap layanan kefarmasian yang sudah pernah dilakukan di Indonesia, tetapi dalam penelitian ini peneliti mengadaptasi instrumen penelitian Jin et al. tahun 2014 yang terdiri domain kesadaran (general awareness), persepsi, harapan serta pengalaman masyarakat terhadap peran apoteker dalam memberikan pelayanan kefarmasian. Sehingga, penelitian ini bertujuan untuk mengetahui kesadaran (general awareness), persepsi, harapan, dan pengalaman masyarakat terhadap peran apoteker dalam memberikan layanan kefarmasian. Penelitian non-eksperimental ini menggunakan metode observasional yang melibatakan apotek di Kecamatan Sokaraja, Baturraden, Sumbang, dan Kedungbanteng. Penentuan apotek sebagai lokasi penelitian dilakukan stratified random sampling pada 23 apotek dan pengambilan sampel responden dengan accidental sampling kepada 110 responden.

\section{Metode}

Penelitian ini merupakan penelitian non-eksperimental dengan metode observasional. Penentuan apotek sebagai lokasi penelitian menggunakan teknik stratified random sampling dan pengambilan sampel responden dengan menggunakan teknik accidental sampling. Apotek yang digunakan sebagai lokasi penelitian adalah apotek yang berada di Kecamatan Sokaraja, Baturraden, Sumbang, dan Kedungbanteng yang telah memenuhi kriteria. Data IAI PC Banyumas pada tahun 2018 menunjukkan jumlah apotek di 4 kecamatan tersebut yaitu 35 
apotek, dengan rincian yaitu 14 apotek di Sokaraja, 7 apotek di Baturraden, 11 apotek di Sumbang, dan 3 apotek di Kedungbanten. Kriteria untuk apotek yang dapat menjadi lokasi dalam penelitian ini adalah sebagai berikut :

1. Apotek bersedia menjadi lokasi penelitian.

2. Apotek bersedia memberikan waktu dan tempat untuk peneliti dalam pengambilan sampel.

3. Apotek yang dapat dijangkau oleh peneliti untuk pengambilan sampel.

4. Apoteker melakukan pelayanan kefarmasian kepada responden

Jumlah apotek pada penelitian ini dihitung dengan berdasarkan pada rumus slovin, jumlah minimal apotek sebagai lokasi dalam penelitian ini adalah 23 apotek. Jumlah minimal apotek tersebut kemudian dibagi untuk menentukan jumlah minimal apotek yang dapat menjadi lokasi penelitian pada masing-masing kecamatan. Pembagian dilakukan secara proporsif sehingga dapat mewakili populasi seluruh apotek.

Populasi dalam penelitian ini adalah seluruh masyarakat yang berada di Kecamatan Sokaraja, Baturraden, Sumbang, dan Kedungbanteng. Berdasarkan data jumlah penduduk Kabupaten Banyumas per Desember tahun 2018, jumlah penduduk di Kecamatan Sokaraja yaitu 87980, Baturraden 53931, Sumbang 91023, dan Kedungbanteng 60838. Sehingga total jumlah penduduk pada 4 kecamatan tersebut adalah 293.772 penduduk. Sampel adalah masyarakat yang berkunjung ke apotek yang memenuhi kriteria inklusi responden sebagai sampel. Pengambilan sampel responden di setiap apotek dilakukan dengan teknik accidental sampling. Kriteria inklusi responden sebagai sampel adalah sebagai berikut :

1. Responden dengan usia yaitu 17-55 tahun (WHO, 2015).

2.Responden bersedia menjadi subjek dalam penelitian yang dibuktikan dengan persetujuan responden dilembar inform consent.

3. Responden bersedia mengisi kuesioner.

4. Responden yang pernah memperoleh layanan kefarmasian oleh apoteker (pelayanan obat resep dan swamedikasi).

Kriteria eksklusi untuk pengambilan sampel responden diantaranya adalah sebagai berikut :

1. Responden yang tidak mampu untuk membaca dan menulis.

2. Responden yang tidak dapat menyelesaikan pengisian kuesioner.

Sampel dihitung dengan menggunakan rumus slovin dan didapatkan bahwa jumlah minimal responden adalah 100 . Kemudian dilakukan penambahan $10 \%$ untuk mengantisipasi adanya drop out sampel atau data yang diperoleh dalam proses penelitian tidak lengkap, sehingga jumlah minimal responden yaitu 110 responden (Sastroasmoro, 2011). Selanjutnya dibagi tiap apotek dan didapatkan responden sejumlah 5 tiap apotek. Uji validitas yang 
dilakukan adalah uji validitas bahasa, isi dan konstruk. Uji validitas konstruk dilakukan pada 30 responden yang berbeda dari sampel penelitian.

Kuesioner yang digunakan diadaptasi dari penelitian Jin et al. (2014) terdiri dari 4 bagian yaitu general awareness masyarakat terhadap peran apoteker, persepsi, harapan, dan pengalaman masyarakat terhadap peran apoteker. Kuesioner terdiri dari 4 bagian dengan berjumlah 20 butir pertanyaan. Bagian pertama berupa pertanyaan mengenai kesadaran (general awareness) masyarakat tentang apoteker dengan alternatif jawaban berupa "Ya" dan "Tidak". Kuesioner bagian kedua berupa pertanyaan mengenai persepsi, bagian ketiga mengenai harapan dan bagian keempat mengenai pengalaman dengan alternatif jawaban berupa "Sangat setuju", "Setuju”, "Tidak setuju” dan "Sangat tidak setuju”.

Skoring kesadaran (general awareness) masyarakat tentang apoteker dengan kuesioner dilakukan berdasarkan skala Guttman (Riduwan, 2010).buy Skala Guttman berupa alternatif jawaban "Ya" dengan skor 1 dan "Tidak" dengan skor 0. Sedangkan pengukuran persepsi, harapan dan pengalaman masyarakat terhadap peran apoteker diukur dengan skala likert dengan skoring adalah " Sangat setuju” dengan skor 4, "setuju " dengan skor 3, " tidak setuju” dengan skor 2, dan " sangat tidak setuju” dengan skor 1 .

Data yang diperoleh kemudian dilakukan analisis secara deskriptif dan uji normalitas untuk mengetahui data tersebut terdistribusi normal atau tidak. Apabila data berdistribusi normal maka kategori dapat dibuat berdasarkan nilai mean, sedangkan apabila data tidak berdistribusi normal maka kategori dapat dibuat berdasarkan nilai median.

\section{Hasil dan Pembahasan}

Penelitian ini telah melalui proses telaah etik yang dilakukan di KEPK (Komisi Etik Penelitian Kesehatan) Fakultas Kedokteran Universitas Jenderal Soedirman. Penelitian ini dinyatakan sebagai penelitian dengan status telaah exempted atau dapat dilakukan tanpa melalui telaah lanjutan dari Komisi Etik Penelitian Kesehatan dengan Nomor Registrasi KEPK 330/KEPK/VIII/2019.

Berdasarkan rencana perhitungan jumlah apotek yang digunakan sebagai lokasi penelitian yaitu 23 apotek dan jumlah sampel responden sebanyak 110 responden. Pengambilan sampel responden di setiap apotek yaitu sebanyak 3-5 responden. Uji validitas bahasa dilakukan dengan penerjemahan kuesioner yang diadaptasi dari penelitian Jin et al. (2014) dari bahasa asing (bahasa Inggris) ke bahasa Indonesia oleh lembaga bahasa resmi ELTI Purwokerto. Uji validitas konstruk melibatkan 30 responden yang mengunjungi apotek Kecamatan Sokaraja, Baturraden, Sumbang, dan Kedungbanteng yang tidak termasuk dalam data penelitian. Analisis statistik dengan SPSS versi 16,0 dilakukan pada tiap butir pertanyaan 
dengan mengkorelasikan antara skor butir pertanyaan dengan skor total. Apabila nilai $r$ hitung $>$ nilai rtabel dengan $\alpha=5 \%$, maka butir pertanyaan d alam kuesioner tersebut dinyatakan valid dengan koefisien korelasi yang signifikan (Sugiyono, 2009). Nilai r tabel untuk 30 responden yaitu 0,361 . Berdasarkan hasil yang diperoleh menunjukkan bahwa masing-masing item pertanyaan kesadaran (general awareness) mempunyai nilai rhitung yang lebih besar dari $r$ tabel yaitu 0,361 , sehingga item pertanyaan dinyatakan valid dan dapat digunakan untuk penelitian.

Hasil yang diperoleh dari kuesioner persepsi masyarakat terhadap peran apoteker pada layanan kefarmasian di Apotek Kecamatan Sokaraja, Baturraden, Sumbang, dan Kedungbanteng yaitu pada kisaran 0,515-0,861, sedangkan untuk hasil dari kuesioner harapan yaitu pada kisaran 0,741 - 0,788, dan untuk kuesioner pengalaman yaitu pada kisaran 0,714 0,843. Berdasarkan hasil tersebut menunjukkan pada masing-masing item pertanyaan mempunyai nilai rhitung yang lebih besar dari rtabel yaitu 0,361, sehingga item pertanyaan pada kuesioner persepsi, harapan, dan pengalaman dinyatakan valid.

\subsection{Karakteristik responden}

Responden pada penelitian ini adalah pengunjung apotek yang memperoleh layanan kefarmasian baik resep maupun non-resep (swamedikasi) oleh apoteker di Apotek Kecamatan Sokaraja, Baturraden, Sumbang, dan Kedungbanteng. Karakteristik responden meliputi jenis kelamin, usia, pendidikan terakhir, pekerjaan, dan frekuensi kunjungan ke apotek per bulan. Adapun karakteristik responden yang diperoleh pada penelitian digambarkan pada tabel 1 .

Berdasarkan hasil yang diperoleh, responden berjenis kelamin perempuan lebih banyak daripada laki-laki. Responden yang berjenis kelamin perempuan lebih peduli terhadap kesehatan yang mencakup obat-obatan, selain itu sumber informasi yang didapat oleh perempuan lebih banyak karena perempuan sering berinteraksi dan lebih aktif daripada lakilaki (Puspasari et al., 2018). Menurut Wahyuni (2012), dibandingkan laki-laki, perempuan lebih rentan terhadap berbagai macam penyakit dan lebih banyak yang berkonsultasi dengan petugas kesehatan.

Pembagian usia responden yang berkunjung ke apotek mengacu pada pembagian usia menurut Depkes RI (2009) yaitu remaja akhir (17 - 25 tahun), dewasa awal (26 -35 tahun), dewasa akhir (36-45 tahun), dan lansia awal (46-55 tahun). Responden yang berkunjung ke apotek paling banyak yang berusia dewasa awal (26-35 tahun) yaitu 38\%, hal ini disebabkan oleh pada usia tersebut kesadaran untuk berobat dan membeli obat ketika merasakan sakit sangat tinggi dibandingkan dengan usia lainnya (Widodo \& Albertus, 2012). Salah satu kriteria inklusi pada penelitian ini yaitu usia 17 hingga 55 tahun, dimana usia tersebut 
merupakan usia produktif (Kemenkes RI, 2016). Pada usia produktif seseorang cenderung mengupayakan untuk menjaga kondisi kesehatannya ketika beraktifitas padat. Selain itu usia produktif akan mempermudah seorang apoteker dalam memberikan informasi obat yang diperoleh, sehingga berpengaruh terhadap tingkat daya tangkap informasi yang diberikan (Anisah et al., 2010).

Tabel 1. Karakteristik Responden di Apotek Kecamatan Sokaraja, Baturraden, Sumbang, dan Kedungbanteng.

\begin{tabular}{|c|c|c|c|}
\hline No & $\begin{array}{l}\text { Karakteristik } \\
\text { responden }\end{array}$ & $\begin{array}{l}\text { Frekuensi } \\
(\mathrm{n}=110)\end{array}$ & Persentase $(\%)$ \\
\hline \multirow[t]{3}{*}{1} & Jenis kelamin & & \\
\hline & a. laki-laki & 49 & 44.5 \\
\hline & b. perempuan & 61 & 55.5 \\
\hline \multirow[t]{5}{*}{2} & Usia & & \\
\hline & a. $17-25$ & 28 & 25 \\
\hline & b. $26-35$ & 38 & 35 \\
\hline & c. $36-45$ & 30 & 27 \\
\hline & d. $46-55$ & 14 & 13 \\
\hline \multirow{6}{*}{3} & Pendidikan & & \\
\hline & Terakhir & & \\
\hline & a. SD & 17 & 16 \\
\hline & b. SMP & 31 & 28 \\
\hline & c. SMA & 52 & 47 \\
\hline & d. Sarjana & 10 & 9 \\
\hline \multirow[t]{7}{*}{4} & Pekerjaan & & \\
\hline & a. Pelajar/ & & \\
\hline & Mahasiswa & 13 & 12 \\
\hline & b. Swasta & 33 & 30 \\
\hline & c. Wirausaha & 13 & 12 \\
\hline & d. PNS & 3 & 3 \\
\hline & e. Lainnya & 48 & 44 \\
\hline \multirow{4}{*}{5} & Frekuensi & & \\
\hline & Kunjungan & & \\
\hline & a. 1 kali & 27 & 24.5 \\
\hline & b. lebih dari 1 kali & 83 & 75.5 \\
\hline
\end{tabular}

Pendidikan terakhir responden pada penelitian dominan pada responden dengan tingkat pendidikan terakhir SMA (47\%), pendidikan SMA atau sederajat termasuk dalam kategori pendidikan menengah atau lanjutan (Supardi \& Raharni, 2006). Pendidikan merupakan faktor yang berpengaruh terhadap daya tangkap informasi, pengetahuan dan sikap kurang minat seseorang terhadap suatu alternatif (Anisah et al., 2010). Semakin tinggi tingkat pendidikan akan cenderung memiliki keinginan untuk memenuhi kebutuhan kesehatan agar hidup lebih sehat (Ruditya \& Chalidyanto, 2015). 
Berdasarkan pekerjaan responden, persentase terbanyak yaitu pada pekerjaan lainnya (44\%) yang meliputi 34 responden ibu rumah tangga, 12 responden buruh, dan 2 responden tidak bekerja. Pendidikan dan pekerjaan adalah dua karakteristik konsumen yang saling berhubungan. Pendidikan akan menentukan jenis pekerjaannya (Sulistya et al., 2017). Pekerjaan seseorang dapat mempengaruhi tingkat aktivitas fisiknya, sedangkan tingkat aktivitas fisik seseorang akan mempengaruhi kesehatannya (Zainuddin et al., 2015).

Frekuensi kunjungan responden ke apotek setiap bulan sebagian besar berkunjung ke apotek $>1 \mathrm{x}$ per bulan $(75,5 \%)$. Sebagian besar responden yang berkunjung ke apotek $>1 \mathrm{x}$ per bulan mengungkapkan bahwa apotek tersebut merupakan langganan mereka dalam memenuhi kebutuhan obat mereka. Konsumen apotek yang menjadi pelanggan, sebagian besar telah memperoleh pelayanan apotek yang sesuai atau melebihi harapan yang diinginkan (Handayani et al., 2009). Konsumen apotek yang merasa senang telah memperoleh pelayanan apotek yang sesuai dengan harapan mereka akan kembali lagi ke apotek untuk membeli obat maupun konsultasi kesehatan.

\subsubsection{Uji normalitas data}

Uji normalitas data pada penelitian ini menggunakan uji Kolmogorov smirnov untuk variabel kesadaran (general awareness), persepsi, harapan, dan pengalaman karena responden lebih dari 50 responden (Dahlan, 2011). Hasil uji normalitas untuk variabel kesadaran (general awareness), persepsi, harapan, dan pengalaman digambarkan pada tabel 2.

Tabel 2. Hasil uji normalitas untuk variabel kesadaran (general awareness), persepsi, harapan, dan pengalaman.

\begin{tabular}{lrc}
\hline Variabel & p-value & Distribusi data \\
\hline General awareness & 0.000 & Tidak normal \\
Persepsi & 0.000 & Tidak normal \\
Harapan & 0.000 & Tidak normal \\
Pengalaman & 0.000 & Tidak normal \\
\hline
\end{tabular}

Kemudian dilakukan kategorisasi berdasarkan nilai mean atau median. Apabila data berdistribusi normal maka kategori dapat dibuat berdasarkan nilai mean, sedangkan apabila data tidak berdistribusi normal maka kategori dapat dibuat berdasarkan nilai median. Pada penelitian ini, data tidak berdistribusi normal, sehingga untuk kategori dibuat dengan nilai median. Jika total skor jawaban tiap responden $\geq$ nilai median maka termasuk dalam kategori "Baik", sedangkan jika total skor jawaban tiap responden < nilai median maka termasuk dalam kategori "Kurang Baik" (Arikunto, 2010).

3.1.2. Kesadaran (General Awareness) masyarakat terhadap peran apoteker di apotek kecamatan Sokaraja, Baturraden, Sumbang, dan Kedungbanteng 
Kesadaran (general awareness) masyarakat terhadap peran apoteker perlu diketahui untuk mengukur pemahaman dan pengetahuan masyarakat akan peran apoteker dalam memberikan layanan kefarmasian di apotek. Kesadaran (general awareness) masyarakat di Kecamatan Sokaraja, Baturraden, Sumbang, dan Kedungbanteng terhadap peran apoteker secara kategori digambarkan pada tabel 3.

Tabel 3. Kategori kesadaran (general awareness) masyarakat terhadap peran apoteker di Apotek Kecamatan Sokaraja, Baturraden, Sumbang, dan Kedungbanteng.

\begin{tabular}{lcccc}
\hline \multirow{2}{*}{ Variabel } & \multirow{2}{*}{$\begin{array}{l}\text { Nilai } \\
\text { median }\end{array}$} & \multicolumn{2}{c}{ Hasil N (\%) } \\
\cline { 3 - 5 } & & 7.00 & $72(65.45)$ & $38(34.55)$ \\
\hline $\begin{array}{l}\text { Kesadaran } \\
\text { awareness })\end{array}$ & (general & & Baik & Kurang baik \\
\hline
\end{tabular}

Berdasarkan nilai median kesadaran (general awareness), apabila total skor jawaban tiap responden $\geq 7,00$ maka termasuk dalam kategori "Baik", sedangkan jika total skor jawaban tiap responden $<7,00$ maka termasuk dalam kategori "Kurang Baik". Oleh karena itu, hasil yang diperoleh menunjukkan $65,45 \%$ masyarakat memiliki kesadaran (general awareness) yang baik terhadap peran apoteker, sehingga peran apoteker pada layanan kefarmasian sudah cukup diketahui dan dipahami oleh masyarakat.

Nilai median untuk kesadaran (general awareness) adalah 7,00 sehingga persentase minimum untuk tiap item pertanyaan adalah $87,5 \%$. Oleh karena itu apabila persentase jawaban pada item pertanyaan adalah $<87,5 \%$ maka aspek pada item pertanyaan tersebut perlu diperbaiki agar dapat meningkatkan kesadaran (general awareness) masyarakat terhadap peran apoteker pada layanan kefarmasian di Apotek. Berdasarkan tabel diatas, terdapat beberapa item pertanyaan yang memperoleh hasil persentase $<87,5 \%$ yaitu item pertanyaan $1,2,5$ dan 7 .

Berdasarkan hasil yang diperoleh untuk item pertanyaan 1 yaitu hanya $49 \%$ responden yang mengenal dan tahu siapa apoteker yang melayani mereka. Sebagian besar dari mereka mengungkapkan kurang mengenal apoteker baik peranannya di apotek maupun nama apoteker yang melayani mereka. Keberadaan apoteker di apotek untuk memberikan layanan kefarmasian kepada masyarakat diketahui oleh 86 (78\%) responden. Salah satu faktor yang mengakibatkan masyarakat kurang mengenal apoteker yaitu kurangnya tanda pengenal yang digunakan oleh apoteker pada saat berpraktik. Selama proses penelitian, dari 23 apoteker yang berpraktik di Apotek Kecamatan Sokaraja, Baturraden, Sumbang, dan Kedungbanteng peneliti hanya melihat 2 apoteker yang menggunakan jas praktik apoteker. Dengan demikian, untuk membantu masyarakat mengenal apoteker yang berpraktek di apotek, perlu ditingkatkan penampilan fisik apoteker yaitu dengan penggunaan name tag dan jas praktik apoteker atau 
atribut lain yang dapat membedakan apoteker dengan petugas apotek lainnya (Hutami \& Rokhman, 2013).

Tabel 4. Gambaran persentase jawaban responden pada kuesioner (general awareness) di Apotek Kecamatan Sokaraja, Baturraden, Sumbang, dan Kedungbanteng.

\begin{tabular}{|c|c|c|c|c|}
\hline No & Pertanyaan & $\begin{array}{c}\text { Jawaban } \\
\text { Ya } \\
\end{array}$ & $\begin{array}{c}\text { Jawaban } \\
\text { Tidak } \\
\end{array}$ & $\begin{array}{c}\text { Persentase } \\
(\%)\end{array}$ \\
\hline 1 & $\begin{array}{l}\text { Apakah Anda mengenal } \\
\text { siapa Apoteker? }\end{array}$ & 54 & 56 & 49,1 \\
\hline 2 & $\begin{array}{l}\text { Ketika Anda pergi ke } \\
\text { apotek, apakah Anda } \\
\text { melihat Apoteker sedang } \\
\text { berpraktek / } \\
\text { memberikan pelayanan? }\end{array}$ & 86 & 24 & 78,2 \\
\hline 3 & $\begin{array}{l}\text { Apakah Anda tahu bahwa } \\
\text { Apoteker dapat } \\
\text { membantu pengobatan } \\
\text { anda? }\end{array}$ & 98 & 12 & 89,1 \\
\hline 4 & $\begin{array}{l}\text { Apakah Anda merasa } \\
\text { nyaman } \\
\text { berkomunikasi dengan } \\
\text { Apoteker mengenai } \\
\text { penyakit dan pengobatan } \\
\text { anda? }\end{array}$ & 103 & 7 & 93,6 \\
\hline 5 & $\begin{array}{l}\text { Apakah Anda pernah } \\
\text { berkomunikasi dengan } \\
\text { Apoteker terkait obat yang } \\
\text { Anda dapatkan? }\end{array}$ & 92 & 18 & 83,6 \\
\hline 6 & $\begin{array}{l}\text { Apakah Anda yakin dengan } \\
\text { saran Apoteker } \\
\text { terkait obat Anda? }\end{array}$ & 103 & 7 & 93,6 \\
\hline 7 & $\begin{array}{l}\text { Apakah Anda yakin } \\
\text { terhadap saran dari } \\
\text { Apoteker terkait informasi } \\
\text { lain selain obat? }\end{array}$ & 92 & 18 & 83,6 \\
\hline 8 & $\begin{array}{l}\text { Apakah Anda puas dengan } \\
\text { pelayanan yang } \\
\text { diberikan oleh Apoteker? }\end{array}$ & 105 & 5 & 95,5 \\
\hline
\end{tabular}

Komunikasi antara apoteker dengan konsumen apotek dapat dilakukan ketika melakukan pemberian informasi obat melalui konseling dan pelayanan informasi obat (Abdullah et al., 2010). Komunikasi dibutuhkan dalam setiap peran apoteker saat memberikan pelayanan kefarmasian, salah satunya yaitu konseling. Komunikasi dalam konseling dapat mempermudah dalam menggali informasi dari pasien meliputi kondisi pasien dan informasi yang dibutuhkan oleh pasien, serta dapat mengetahui pemahaman dan pengetahuan pasien akan pengobatannya. Ketika pasien kurang paham dengan pengobatannya maka apoteker 
dapat memberikan saran dan informasi untuk meningkatkan pengetahuan pasien sehingga outcome therapy dapat tercapai secara optimal (Lutfiyati et al., 2016).

3.1.3. Persepsi masyarakat terhadap peran apoteker di apotek Kecamatan Sokaraja, Baturraden, Sumbang, dan Kedungbanteng.

Persepsi konsumen terhadap peran apoteker menjadi indikator dalam pemenuhan harapan konsumen. Persepsi juga menjadi faktor penting untuk membantu apoteker mengembangkan perannya dalam pelayanan kesehatan dan modal untuk meningkatkan kualitas layanan (Hutami dan Rokhman, 2013). Persepsi masyarakat di Kecamatan Sokaraja, Baturraden, Sumbang, dan Kedungbanteng terhadap peran apoteker secara kategori digambarkan pada tabel 5.

Tabel 5.Kategori Persepsi masyarakat terhadap peran apoteker di Apotek Kecamatan Sokaraja, Baturraden, Sumbang, dan Kedungbanteng.

\begin{tabular}{clll}
\hline Variabel & Nilai median & \multicolumn{2}{c}{ Hasil N (\%) } \\
\cline { 3 - 4 } & & Baik & Kurang baik \\
\hline Persepsi & 12.00 & $70(63.64)$ & $40(36,36)$ \\
\hline
\end{tabular}

Berdasarkan nilai median persepsi, apabila total skor jawaban tiap responden $\geq 12,00$ maka termasuk dalam kategori "Baik", sedangkan jika total skor jawaban tiap responden < 12,00 maka termasuk dalam kategori "Kurang Baik". Oleh karena itu, hasil yang diperoleh menunjukkan 63,64\% masyarakat memiliki persepsi yang baik terhadap peran apoteker pada layanan kefarmasian di apotek. Hasil ini lebih rendah dari penelitian Handayani et al. (2009) yang menunjukkan $74,5 \%$ konsumen apotek memiliki persepsi baik terhadap layanan kefarmasian di apotek, serta penelitian oleh Winanto (2013) bahwa 74,03\% konsumen apotek memiliki persepsi baik terhadap pelayanan apotek oleh apoteker di Kota Ranai Kabupaten Natuna.

Nilai median untuk persepsi adalah 12,00 sehingga batas persentase terendah untuk tiap item pertanyaan adalah $75 \%$. Oleh karena itu apabila persentase jawaban pada item pertanyaan adalah $<75 \%$ maka aspek pada item pertanyaan tersebut perlu diperbaiki agar dapat meningkatkan persepsi masyarakat terhadap peran apoteker pada layanan kefarmasian di Apotek. Berdasarkan tabel diatas, terdapat beberapa item pertanyaan yang memperoleh hasil persentase $<75 \%$ yaitu item pertanyaan 3 dan 4 .

Pada peran apoteker dalam melakukan evaluasi dan monitoring pengobatan memperoleh respon dari responden sebanyak 69,8\% dan 70\%. Menurut sebagian apoteker, mereka melakukan monitoring kepada pasien swamedikasi dengan menggunakan SMS atau WA. Kewajiban apoteker dalam melakukan evaluasi dan monitoring penggunaan obat belum 
sepenuhnya dilakukan karena standar pelayanan tersebut belum dilaksanakan sepenuhnya oleh apotek serta belum dikenal atau tersosialisasi kepada konsumen apotek. Kurangnya waktu apoteker untuk berpraktik di apotek merupakan faktor lain yang mempengaruhi belum terlaksananya evaluasi dan monitoring (Mulyani et al., 2013). Selain itu dapat disebabkan karena tidak semua penyakit yang dikeluhkan oleh responden perlu dilakukan evaluasi dan monitoring. Pasien yang memerlukan evaluasi dan monitoring, seperti lansia, ibu hamil atau menyusui, anak-anak, menerima obat lebih dari 5 jenis, obat dengan indeks terapi sempit, obat yang sering menyebabkan reaksi obat yang merugikan dan pasien yang mengalami gangguan ginjal atau hati (Kemenkes RI, 2016).

Tabel 6. Gambaran Persentase Jawaban Responden pada Tiap Pernyataan Kuesioner Persepsi di Apotek Kecamatan Sokaraja, Baturraden, Sumbang, dan Kedungbanteng.

\begin{tabular}{clc}
\hline No & \multicolumn{1}{c}{ Pertanyaan } & $\begin{array}{c}\text { Persentase skoring } \\
(\mathbf{\%})\end{array}$ \\
\hline 1 & $\begin{array}{l}\text { Apoteker memberikan edukasi / } \\
\text { informasi terkait obat kepada } \\
\text { pasien }\end{array}$ & 81.1 \\
& $\begin{array}{l}\text { Apoteker mengidentifikasi dan memberikan } \\
\text { solusi } \\
\text { terkait permasalahan pengobatan pasien }\end{array}$ & 77.5 \\
\hline 3 & $\begin{array}{l}\text { Apoteker melakukan evaluasi } \\
\text { terkait pengobatan pasien }\end{array}$ & 69.8 \\
\hline 4 & $\begin{array}{l}\text { Apoteker melakukan monitoring } \\
\text { terkait hasil pengobatan pasien }\end{array}$ & 70 \\
\hline
\end{tabular}

3.1.4. Harapan masyarakat terhadap peran apoteker Kecamatan Sokaraja, Baturraden, Sumbang, dan Kedungbanteng.

Pengukuran harapan dilakukan untuk mengetahui peran apoteker yang diinginkan oleh konsumen apotek. Hal ini dapat lebih memudahkan apoteker untuk memberikan pelayanan sesuai dengan kebutuhan konsumen, sehingga kebutuhan konsumen dapat terpenuhi dan apoteker serta apotek memperoleh kepercayaan dari konsumen apotek (Aurelia, 2013). Harapan masyarakat di Kecamatan Sokaraja, Baturraden, Sumbang, dan Kedungbanteng terhadap peran apoteker pada layanan kefarmasian di apotek secara kategori digambarkan pada tabel 7 .

Tabel 7.Kategori Harapan masyarakat terhadap peran apoteker di Apotek Kecamatan Sokaraja, Baturraden, Sumbang, dan Kedungbanteng.

\begin{tabular}{cclc}
\hline Variabel & Nilai median & \multicolumn{2}{c}{ Hasil N (\%) } \\
\cline { 3 - 4 } & & Baik & Kurang baik \\
\hline Harapan & 14.00 & $65(59,09)$ & $45(40,91)$ \\
\hline
\end{tabular}


Berdasarkan nilai median harapan, apabila total skor jawaban tiap responden $\geq 14,00$ maka termasuk dalam kategori "Baik", sedangkan jika total skor jawaban tiap responden < 14,00 maka termasuk dalam kategori "Kurang Baik". Oleh karena itu, hasil yang menunjukkan 59,09\% masyarakat memiliki harapan yang baik terhadap peran apoteker pada layanan kefarmasian di apotek. Hasil tersebut menunjukkan harapan masyarakat yang baik terhadap peran apoteker pada layanan kefarmasian cukup tinggi, sehingga apoteker perlu meningkatkan kualitas layanan yang sesuai dengan harapan masyarakat. Hasil yang diperoleh sesuai dengan penelitian yang mengungkapkan harapan konsumen apotek dalam pengembangan layanan kefarmasian oleh apoteker cukup tinggi, khususnya pada kemudahan untuk dihubungi diluar jam kerja $(80 \%)$ dan melakukan pemantauan atau evaluasi terapi (73,25\%) (Hutami \& Rokhman, 2013).

Pengukuran secara kuantitatif untuk memperoleh hasil persentase jawaban responden pada tiap pernyataan harapan masyarakat terhadap peran apoteker pada layanan kefarmasian di apotek ditunjukkan pada tabel 8. Nilai median untuk persepsi adalah 14,00 sehingga batas persentase terendah untuk tiap item pertanyaan adalah $87,5 \%$. Oleh karena itu apabila persentase jawaban tiap item pertanyaan adalah $<87,5 \%$ maka aspek pada item pertanyaan tersebut perlu diperbaiki agar dapat meningkatkan harapan masyarakat terhadap peran apoteker pada layanan kefarmasian di Apotek. Berdasarkan tabel diatas, terdapat beberapa item pertanyaan yang memperoleh hasil persentase $<87,5 \%$ yaitu item pertanyaan 1 dan 4 .

Tabel 8. Gambaran Persentase Jawaban Responden pada Tiap Pernyataan Kuesioner Harapan di Apotek Kecamatan Sokaraja, Baturraden, Sumbang, dan Kedungbanteng.

\begin{tabular}{clc}
\hline No & \multicolumn{1}{c}{ Pertanyaan } & $\begin{array}{c}\text { Persentase } \\
\text { skoring } \\
(\mathbf{\%})\end{array}$ \\
\hline 1 & $\begin{array}{l}\text { Saya berharap Apoteker bertanggung } \\
\text { jawab dalam mengatasi permasalahan } \\
\text { terkait obat }\end{array}$ & 86.6 \\
\hline 2 & $\begin{array}{l}\text { Saya berharap Apoteker memiliki } \\
\text { pengetahuan tentang obat }\end{array}$ & 88.9 \\
\hline 3 & $\begin{array}{l}\text { Saya berharap Apoteker memberikan } \\
\text { edukasi kepada saya tentang cara } \\
\text { penggunaan obat yang aman dan tepat }\end{array}$ & 89.5 \\
\hline 4 & $\begin{array}{l}\text { Saya berharap Apoteker mengawasi } \\
\text { respon terapi pengobatan dan } \\
\text { membantu saya jika mengalami } \\
\text { masalah yang berhubungan dengan } \\
\text { obat }\end{array}$ \\
\hline
\end{tabular}

3.1.5. Pengalaman masyarakat terhadap peran apoteker di Apotek Kecamatan Sokaraja, Baturraden, Sumbang, dan Kedungbanteng. 
Pengukuran pengalaman masyarakat terhadap peran apoteker dilakukan untuk mengetahui sejauh mana peran apoteker yang sudah dirasakan oleh masyarakat. Pengalaman masyarakat di Kecamatan Sokaraja, Baturraden, Sumbang, dan Kedungbanteng terhadap peran apoteker pada layanan kefarmasian di apotek secara kategori digambarkan pada tabel 9.

Tabel 9. Kategori Pengalaman masyarakat terhadap peran apoteker di Apotek Kecamatan Sokaraja, Baturraden, Sumbang, dan Kedungbanteng.

\begin{tabular}{cccc}
\hline Variabel & Nilai median & \multicolumn{2}{c}{ Hasil N (\%) } \\
\cline { 3 - 4 } & & Baik & Kurang baik \\
\hline Pengalaman & 12.50 & $55(50)$ & $55(50)$ \\
\hline
\end{tabular}

Berdasarkan nilai median pengalaman, apabila total skor jawaban tiap responden $\geq$ 12,50 maka termasuk dalam kategori "Baik", sedangkan jika total skor jawaban tiap responden < 12,50 maka termasuk dalam kategori "Kurang Baik". Oleh karena itu, hasil yang diperoleh menunjukkan $50 \%$ masyarakat memiliki pengalaman yang baik terhadap peran apoteker pada layanan kefarmasian di apotek. Dengan demikian, dapat diketahui bahwa responden cukup memiliki pengalaman atau pernah merasakan adanya peran apoteker serta memahami peran apoteker dalam memberikan layanan kefarmasian. Pengalaman sangat berkaitan dengan hasil persepsi yang diperoleh. Pengalaman yang pernah dirasakan oleh seseorang akan membentuk kepercayaan yang dicirikan dengan adanya persepsi positif atau baik karena telah terpenuhinya harapan yang diinginkan (Tjong, 2013).

Tabel 10.Gambaran Persentase Jawaban Responden pada Tiap Pernyataan Kuesioner Pengalaman di Apotek Kecamatan Sokaraja, Baturraden, Sumbang, dan Kedungbanteng.

\begin{tabular}{|c|c|c|}
\hline No & Pertanyaan & Persentase skoring (\%) \\
\hline 1 & $\begin{array}{l}\text { Berdasarkan pengalaman saya, } \\
\text { Apoteker merupakan sumber } \\
\text { informasi obat yang dapat } \\
\text { dipercaya }\end{array}$ & 81.8 \\
\hline 2 & $\begin{array}{l}\text { Berdasarkan pengalaman saya, } \\
\text { Apoteker merupakan tenaga } \\
\text { profesional kesehatan yang penting } \\
\text { dalam sistem kesehatan }\end{array}$ & 82.5 \\
\hline 3 & $\begin{array}{l}\text { Berdasarkan pengalaman saya, } \\
\text { Apoteker memberikan saran dan } \\
\text { informasi sehubungan dengan } \\
\text { penggunaan obat yang aman dan } \\
\text { tepat }\end{array}$ & 83.9 \\
\hline 4 & $\begin{array}{l}\text { Berdasarkan pengalaman saya, } \\
\text { Apoteker bertanggung jawab dalam } \\
\text { mengatasi masalah yang berhubungan } \\
\text { dengan obat }\end{array}$ & 80.9 \\
\hline
\end{tabular}


Pengukuran secara kuantitatif untuk memperoleh hasil persentase jawaban responden pada tiap pernyataan pengalaman masyarakat terhadap peran apoteker pada layanan kefarmasian di apotek ditunjukkan pada tabel 10.

\section{Kesimpulan}

Kesadaran (general awareness) masyarakat terhadap peran apoteker pada layanan kefarmasian di apotek di Kecamatan Sokaraja, Baturraden, Sumbang, dan Kedungbanteng menunjukkan tingkat yang baik sebanyak 65,45\%. Masyarakat di Kecamatan Sokaraja, Baturraden, Sumbang, dan Kedungbanteng 63,64\% memiliki persepsi baik terhadap peran apoteker, 59,09\% memiliki harapan yang baik terhadap peran apoteker dan 50\% memiliki pengalaman yang baik terhadap peran apoteker pada layanan kefarmasian di apotek.

\section{Daftar Pustaka}

Abdullah, N. A., Andrajati, R., dan Supardi, S. (2010). Pengetahuan, sikap dan kebutuhan pengunjung apotek terhadap informasi obat di kota Depok. Buletin Penelitian Sistem Kesehatan, 13(4): pp. 344-352.

Anisah, Z., Moeslich, H., dan Didik, S. (2010). Pengaruh Pelayanan Kefarmasian Terhadap Kepuasan Konsumen Apotek Di Wilayah Purwokerto. Jurnal Farmasi Indonesia, 7(01): pp. 46-52.

Arikunto, S. (2010). Prosedur Penelitian : Suatu Pendekatan Praktik, Rineka Cipta, Jakarta.

Aryunadi, Y.F. (2014). Evaluasi Penerapan Standar Pelayanan Kefarmasian di Apotek di Kabupaten Banyumas, Skripsi, Jurusan Farmasi Universitas Jenderal Soedirman, Purwokerto.

Aurelia, Erlin. (2013). Harapan dan Kepercayaan Konsumen Apotek terhadap Peran Apoteker yang Berada di Wilayah Surabaya Barat. Calyptra: Jurnal Ilmiah Mahasiswa Universitas Surabaya, 2(01): pp. 01-20.

Dahlan, M. S. (2011). Statistik untuk Kedokteran dan Kesehatan, Penerbit Salemba, Jakarta.

Depkes RI. (2009). Profil Kesehatan Indonesia Tahun 2008. Departemen Kesehatan RI, Jakarta.

Fajarini, H. (2018). Implementasi Peraturan Menteri Kesehatan RI No. 73 Tahun 2016 Tentang Standar Pelayanan Kefarmasian di Apotek. Jurnal Ilmiah Farmasi, 7 (2): pp. 260-269.

Handayani, R. S., Raharni, R., dan Gitawati, R. (2009). Persepsi Konsumen Apotek terhadap Pelayanan Apotek di Tiga Kota di Indonesia. Makara Journal of Health Research, 13(1): pp. 22-26.

Hutami, S. T., dan Rokhman, M. R. (2013). Persepsi dan Harapan Konsumen Apotek terhadap Apoteker Farmasi Komunitas. Indonesian Journal of Clinical Pharmacy, 2(3): pp. 85-93.

Jin, X., Azhar, S., Murtaza, G., Xue, F., Mumtaz, A., Niu, H. dan Zhang, Y. (2014). Quantitative study evaluating perception of general public towards role of pharmacist in health care system of Pakistan. Acta Poloniae Pharmaceutica - Drug Research, 71(5), pp. 869-875.

Kemenkes RI. (2016). Standar Pelayanan Kefarmasian di Apotek Nomor 73, Kementerian Kesehatan RI, Jakarta.

Lutfiyati, H., Yuliastuti, F., dan Dianita, P. S. (2016). Pelaksanaan Konseling Oleh Apoteker di Apotek Kecamatan Temanggung. Jurnal Farmasi Sains dan Praktis, 2(1): pp. 24-29. 
Mulyani, Y., Hasanmihardja, M., dan Siswanto, A. (2013). Persepsi Pasien Apotek Terhadap Pelayanan Apotek Di Kabupaten Wonosobo. Jurnal Farmasi Indonesia (Pharmaceutical Journal of Indonesia), 10(1): pp. 55-64

Puspasari, H., Harida, S., dan Fitriyani, D. (2018). Tingkat Pengetahuan Tentang "DAGUSIBU" Obat Antibiotik Pada Masyarakat Desa Sungai Awan Kiri Kecamatan Muara Pawan Kabupaten Ketapang Tahun 2017. Medical Sains, 3(1): pp. 11-18.

Riduwan. (2010). Skala Pengukuran Variabel-variabel Penelitian, Alfabeta, Bandung.

Ruditya, A. N., dan Chalidyanto, D. (2015). Hubungan Karakteristik Individu terhadap Penilaian Kualitas Produk Apotek Rawat Jalan. Jurnal Administrasi Kesehatan Indonesia, 3(2): pp. 108-117.

Sastroasmoro, S. (2011). Dasar-dasar Metodologi Penelitian Klinis Edisi Ke-4, CV Sagung Seto, Jakarta

Sugiyono. (2009). Metode Penelitian Pendidikan (Pendekatan Kuantitatif, Kualitatif dan $R \& D)$, Alfabeta, Bandung.

Sulistya, Y. A., Pramestutie, H. R., dan Sidharta, B. (2017). Profil Kualitas Pelayanan Resep oleh Apoteker di Beberapa Apotek Kecamatan Klojen Kota Malang. Pharmaceutical Journal of Indonesia, 3(1): pp. 1-9.

Supardi, S., dan Raharni. (2006). Penggunaan Obat yang Sesuai dengan Aturan dalam Pengobatan Sendiri Keluhan Demam-Sakit kepala, Batuk dan Flu. Jurnal Kedokteran Yarsi, 14(1): pp. 61-69

Tjong, J. A. (2013). Harapan Dan Kepercayaan Konsumen Apotek Terhadap Peran Apoteker Yang Berada Di Wilayah Surabaya Timur. Calyptra, 2(2): pp. 1-16.

Wahyuni, N.S. (2012). Faktor-faktor yang Berhubungan dengan Pemanfaatan Pelayanan Kesehatan di Puskesmas Sumber Rejo Kota Balikpapan Provinsi Kalimantan Timur Tahun 2012, Skripsi, Fakultas Kesehatan Masyarakat Universitas Indonesia, Jakarta.

Wathoni, N., dan Rahayu, S. A. (2014). A survey of consumer expectation in community pharmacies in Bandung, Indonesia. Journal of Applied Pharmaceutical Science, 4(1): pp. 84-90.

WHO. (2015). World Report On Ageing and Health, World Health Organization, Geneva

Widodo, S. T., dan Albertus, Y.Y. (2012). Persepsi Konsumen Terhadap Kualitas Layanan Kefarmasian di Apotek. Jurnal Penelitian, 16(1).

Winanto, A. (2013). Persepsi Konsumen Terhadap Pelayanan Apotek Di Kota Ranai Kecamatan Bunguran Timur Kabupaten Natuna. Jurnal Mahasiswa Farmasi Fakultas Kedokteran UNTAN.

Zainuddin, M., Utomo, W., Herlina. (2015). Hubungan Stres dengan Kualitas Hidup Penderita Diabetes Mellitus Tipe 2. Jurnal JOM, 2(1).

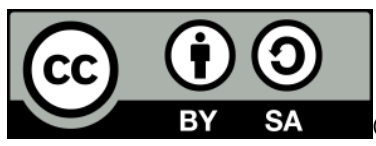

C 2020 by the authors. Submitted for possible open access publication under the terms and conditions of the Creative Commons Attribution-ShareAlike 4.0 International (CC BY-SA 4.0) license (https://creativecommons.org/licenses/by-sa/4.0/). 